\title{
A literature review of the twinning approach in supporting developmental water services by water services institutions (WSIs) and water services authorities (WSAs) in South Africa
}

\author{
Fumene George Tsibani* \\ Department of Water Affairs and Forestry, Private Bag X313, Pretoria 0001, South Africa
}

\begin{abstract}
The purpose of this paper is to review international literature and to contextualise it to South Africa's water services institutions. On the basis of the literature evidence, the following questions will be discussed:

- How is "twinning" to be conceptualised and operationalised

- What are the expected outputs and outcomes of implementation of the twinning approach

- How to draw the lessons from international literature for implementing a twinning approach in South Africa's water services institutions and exploit the benefits thereof

While it is often not feasible to measure success of an approach in a scientific fashion, this paper shows that this less- researched approach can improve integrated strategic objectives of developmental water services and co-operative governance in South African spheres of government in general and water services institutions in particular. Inductively, it is recommended that the hands-on support on developmental water services in South Africa provides an opportunity to explore and exploit the twinning approach benefits and outcomes thereof. Such benefits and outcomes include, inter alia, addressing WSAs and WSIs capacity constraints for implementation of developmental water services reforms as per national targets described in the Water Services Strategic Framework (2003) and other pieces of legislation pursuant to post-Apartheid local government developmental agenda (LGDA).
\end{abstract}

Keywords: capacity building, decentralisation, devolution of powers, Local Government, Organisational Development, pairing, support programmes, twinning, water services

\author{
Abbreviations \\ CBOs community-based organisations \\ CMAs catchment management agencies \\ DPLG Department of Provincial and Local Government \\ DORA Division of Revenue Act \\ DTI Department of Trade and Industry \\ DWAF Department of Water Affairs and Forestry \\ IDPs integrated development plans \\ MoC memorandum of co-operation \\ NEPAD New Partnership for Africa's Development \\ NGOs non-governmental organisations \\ Norad Norwegian International Development \\ Co-operation Agency \\ O\&M operation and maintenance \\ PPPs private public partnerships \\ SADC South African Development Community \\ SALGA South African Local Government Association \\ Sida Swedish International Development Agency \\ TA technical assistance \\ WSAs water services authorities \\ WSDPs water services development plans \\ WSIs water services institutions
}

\footnotetext{
* Unless advised otherwise, this paper represents the views of the author and does not necessarily reflect the official position of the Department of Water Affairs and Forestry (DWAF). Thus, views and comments can be forwarded to the author at PO Box 4129, The Reeds, 0158, City of Tshwane, RSA

푠 +2712 336-6545; fax: +2712 336-7283;

e-mail: tsibanig@dwaf.gov.za

Received 16 September 2004; accepted in revised form 4 April 2005.
}

\section{Introduction and background of the twinning approach}

The twinning approach was employed in the early 1980 s by various international co-operation agencies such as Sida and Norad to promote effective institutional capacity building of various countries and their respective institutions. A literature search reveals that if the twinning approach is used in a correct manner, it can be an optimal technique for institutional capacity building and support for general and integrated services. There is general consensus among writers that twinning arrangements should be critically applied to ensure that similar partners are identified in order to focus on the strategic institutional objectives of developmental water services. Van Ryneveld and Sproule (2005)supported by Brikke (2000)and Tsibani (2004) describe developmental water services as an agglomeration of a number of disparate disciplines such as engineering, environment, programme management, health, education, development and policy in order to meet the water supply and sanitation services of the present by 2008 and 2010 respectively without compromising the needs of the future generations. The term "developmental water services" is coined by Van Ryneveld and Sproule (2005). This will ensure that the selection of key officials and the management of the twinning arrangement are taken into consideration. Therefore, the twinning approach should be seen as a new way of dealing with "developmental water services" implementation and operational issues rather than as a prescribed practice. This requires a greater conceptual clarity by stakeholders and institutions involved. It goes without saying that all parties or institutions should give more attention to governance and strategic administrative management issues before any kind of twin- 
ning, matching, or pairing implementation is being explored. It is suggested that this pairing, or twinning approach should be addressed in a conducive and equal partnership environment of institutions on the twinning arrangement, if developmental water services delivery and sustainable institutional capacity building are to be attained. In view of this, the paper attempts to present innovative ideas on how the twinning approach can be contextualised in WSIs especially WSAs in South Africa.

The purpose of this paper is neither to duplicate the existing approaches nor to embark on a new approach that would bypass the initiatives that are already in motion by the water sector. Rather the aim is to explore and exploit the benefits of the twinning approach to address some of the challenges and constraints for delivering developmental water services. Such a focus on this less-researched approach in South Africa should fit in with the current capacity building and training support strategies and other collaborative initiatives in the water services sector, and at the same time allow the twinning approach to make a unique contribution to the process of enhancing the capacity of water services institutions in order to have developmental water services within the context of the greater community milieu in South Africa. Yet, despite compelling literature evidence about the positive benefits and outcomes of a twinning approach, it is equally critical that the approach is not euphorically regarded as the Deus ex machina for the cure of WSI and WSA developmental water services constraints which are often closely related to theories of change in South Africa, Africa and elsewhere (Tsibani, 2004; Slater; 1989; Campbell, 1988; Morah, 1996). The latter is due to the argument advanced by Olowu (1994) that some of the required changes for developmental water services largely depend on socio-economic, political and developmental metaphysical changes in the region (e.g. SADC), Africa and world. Tsibani (2004) explored and describes this term in detail within the context of developmental local government (or modernisation) agenda in South Africa. In this study, Tsibani (2004) stresses the notion that all Acts of Parliament must be seen as a strong chain or spine for DLGA (as derived from the White Paper on Local Government, March 1998) within the context of ever-changing metaphysical environment at local level.

\section{Context for twinning approach}

According to the Constitution of the Republic of South Africa, (Act 108 of 1996) a municipality is "a sphere of government" on its own, which has among other functions, the responsibility of ensuring the provision of [basic water] services to communities in a sustainable manner, and to promote social and economic development within their areas of jurisdiction. In order to fulfil this developmental water services function, a municipality or a water services authority (WSA) must structure and manage its administrative management, budget, and planning processes to give priority to the basic needs of the community, and to promote socio-economic, and political development. In line with this constitutional requirement, all municipalities are expected to develop an integrated development plans in accordance with the Municipal System Act of 2000 (as amended), Water Services Act, Act 108 of 1997 and Municipal Structures Act of 1998, Act 117 of 1998, Division of Revenue Act, Act No. 1 of 2005, Section 6A (This Act is amended on an annual basis), and White Paper on Local Government (March, 1998).

There is a general agreement in these Acts that municipalities must assume their powers and functions as authorities for the development of their areas and to arrive at speedy and appropriate decision-making and implementation of services. For the purpose of this paper, which focuses on water services institutions in terms of the Water Services Act, Act 108 of 1997 (hereafter referred to as the Act), the Act requires water services authorities in particular to provide water services (defined as water supply and sanitation) within their areas through WSDPs as a chapter of IDPs.

The Act sets out the institutional development framework, which outlines the roles and responsibilities of water services authorities in particular among other institutions mentioned in various pieces of legislation. These basic [water] services (Section 6 (2) (a) of the Municipal Systems Act, and Section 73 (1) (c) of the Municipal Structures Act read with Sections 152-3 of the Constitution including 27 (1) (a-c) of the same Act) .or any part thereof, include:

- Collecting revenue and tariffs in terms of the provision or management of water services

- Developing WSDPs in line with institutional development

- Managing the provision and development of waterworks

- Legislating and regulating, and planning water services

- Ensuring water services provision and ensuring infrastructure provision

- Ensuring sustainable, affordable, efficient, effective and reliable water services

In many instances, municipalities as WSAs do not have the capacity to fulfil these powers and functions as stated in various pieces of legislation. This is further complicated by the re-demarcation process, which has serious institutional development impacts on delivery of water services, operation and maintenance $(\mathrm{O} \& \mathrm{M})$ of existing water infrastructure and asset management strategies. Tsibani (2004) argues that "the new municipalities coming from segregationist policies of the past including the impact of transformation in South Africa in a context of new democratic era. ...they are in a state of despair and under-development... characterised by chaotic management, administration systems and an exodus of technical staff without strategic plans".

This situation is unsustainable for transfer and decentralisation of water services to WSAs within the context of the rapidly changing metaphysical world (Tsibani, 2004). From this, it can be argued that it is not the extent of the metaphysical changes alone that is significant for innovative strategies to implement developmental water services by WSAs and WSIs in terms of Sections 152 and 153 of the Constitution, but also "the number of dimensions on which change is taking place, such as global and macro-economic restructuring, periods of prolonged famine, poverty in developing countries, and unemployment, changes in demographic structure, new social norms, and the acceptance of a multi-ethnic society have combined to pose new challenges for local authorities" (Tsibani, 2004).

Based upon the foregoing, it can be argued that WSAs and WSIs in South Africa need to respond to the metaphysical world's changes timeously and effectively (Section 6(2) (a) of the Municipal Systems Act actual words are "the administration of a municipality (or WSA or WSI) ... must be responsive to the needs of the local community"). DWAF as a custodian of water services is primarily responsible to provide support strategies to WSAs and WSIs to respond to the metaphysical changes whereby an action-centred twinning approach is explored and exploited to deal effectively with the delivery of developmental water services.

Yet, whether institutional capacity building support programmes "work" or not has been debated by various research and academic institutions more than 40 years ago. On close in- 
spection of the work of leading social scientists in local government support, the result is surprising: the different support programmes and approaches totally neglect the twinning approach. Although extensive research by scholars has been undertaken in the field of institutional capacity building and training, there is limited reference to twinning or pairing of municipalities, WSIs, WSAs and /or countries. However, the writer wishes to acknowledge the twinning approaches implemented by Sida, and Norad in the 1990s in the SADC region inclusive of the recent South African and Cuban twinning approach (in the post-1990s) in addressing water services, health and other essential services particularly in rural communities in South Africa. Yet, this is not enough to address WSAs' and WSIs' constraints to deliver developmental water services. In other words, there is an urgent and greater need to focus on municipal twinning approaches to give effect to the developmental water services agenda within the national and millennium developmental goals in South Africa (Franks, 1998; Cooper; 1984).The main actors in this transitional process tend to neglect peer review, twinning, pairing or matching between WSIs and WSAs and postpone this for the so-called best practice workshops or site visits as opposed to intensive hands-on, or nut and bolt developmental water services issues which are daily confronting WSIs and WSAs practitioners alike. One of the prerequisites for developmental water services is capacitated personnel with technical skills in order to enhance WSIs and WSAs performance thereby able to consolidate LGDA and developmental water services in South Africa.

In the light of the above-mentioned current status quo which is totally unsustainable, this will require a concerted and co-ordinated effort of all the water services institutions such as capacitated local government, water services providers (water boards, CBOs, PPPs, academic and research institutions, CMAs, private sector and non-governmental organisations (NGOs). Although DWAF, DPLG and SALGA have laid the foundation for co-operative governance in dealing with water services and delivery mechanisms as outlined in the MoC, there are noticeable and significant gaps for concerted efforts to have a significant impact on capacitating water services institutions in South Africa. The most fundamental issue for all spheres of government and stakeholders is the need to change into a co-ordinated and integrated developmental mode of thinking. Yet, planning, and implementation approaches to deal with basic needs of communities have not been properly understood and communicated between and within spheres of government, and other water sector partners. The study commissioned by the Presidential Review Committee in 1994, has identified the following gaps and deficiencies in coordinated institutional capacity building and training support programmes and initiatives, which is still relevant and applicable after eleven years of democracy in South Africa:

- The absence of an overall shared vision particularly on the water sector support

- The existence of an inherited bloated bureaucracy (for instance, municipalities have to cope with and adhere to more than 144 pieces of legislation inclusive of sector conditions under DORA, treasury regulations and infrastructure input-driven expenditure under the Municipal Infrastructure Grant (MIG) combined with excessively centralised control, top-down management structures and a work ethic that is not primarily oriented towards [developmental water] services delivery but rather expenditure driven

- The absence of appropriate capacity building and training support and communication strategies, between and within spheres and departments, as well as with the public
- The absence of an effective monitoring and evaluation systems and implementation plan

- Turf battles between officials, individuals and departments, resulting in the duplication of capacity building and support programmes and initiatives

- Often individual-vested interests rather than concerted efforts to implement sustainable institutional capacity building and support programmes and initiatives

- The lack of specific time-frames for commissioning of projects and programmes across departments, resulting in bureaucratic loops, which are often exploited by water services providers.

All the above, though not exhaustive, lead to difficulties in coordinating policy, guidelines and institutional capacity building programmes and/or projects effectively between spheres of government and between different line departments and directorates. The outcome is a great deal of wasted time, energy and resources with a negative impact on developmental water services delivery.

In view the above gaps and deficiencies in institutional support programmes, this paper argues that the twinning approach could lead to a more focused institutional capacity building strategy and support effort. The latter is due to the fact that despite past investment of resources, effective water services institutions and sustainable water services remain major challenges for all to meet the vision and strategic goal of developmental water services within the water sector. Inductively, it can be argued that the desired outcomes for capacity building and support to WSAs and WSIs are therefore made to be a complicated process rather than a smooth process. In this regard, it is a notion of this paper that the twinning approach can be used to achieve the desired outcomes of capacitated WSAs and WSIs whereby disruption of the existing developmental water services will be minimised at all costs.

\section{Conceptualisation and operationalisation of twinning approach}

\section{Preliminary and general definitions}

A number of terms are used to connote the major means (of capacity building) that development co-operation agencies employ. Terms such as capacity building, institution building, and institutional (or organisational) capacity building are used interchangeably. According to Tsibani (2004) the term institutions is a subtle concept, and therefore subject to lack of clarity by stakeholders. In other words, an institutional model, though not limited, includes rules or procedures that shape municipal councils, councillors and officials, and roles and responsibilities of WSAs and WSIs as institutions that have attained special status or legitimacy in terms of various Parliamentary Acts. It can be deduced that a distinguishing characteristic of institutions is a complex exercise that persists over time by serving collectively valued purposes. In a strict sense, the term effective institutions refers to consciously designed institutions that do one or more of the following:

- Surviving over time as identifiable units by Parliamentary Acts or registered as trading companies by the Department of Trade and Industry (DTI)

- Recovering some or even all their costs by having by-laws and regulations on water services 
- Supplying or distributing a continuing stream of developmental water services to beneficiaries

- Employing staff members and/or providers

In light of the above, it is argued that institutional capacity building in practice usually embraces programmes of change in single or twin WSAs or WSIs to improve their developmental water services performance and capacity to develop new capabilities independently. The term is also used to refer to the strengthening or redesign of institutional arrangements in terms of Section 78 of the Municipal Structures Act. From this definition, the term institutional building can connote co-operation either at the level of the institution and/or of networks. In a context of developmental water services, individual and institutional capability and capacity needs should be a key factor in deciding on the form that institutional building and a twinning approach thereof. Thus, it is essential that issues of interpretation by the different WSIs and WSAs involved in this proposed twinning approach be explored and aligned as early as possible, so that differences of expectations can be minimised. Based upon these definitions, I will attempt to operationalise "twinning approach" in South Africa thereby exploring and exploiting its "benefits and outcomes" thereof.

\section{Operationalisation of twinning approach in WSAs and WSIs in South Africa}

According to Askvik (1999) twinning is the distinctive approach employed by Sida and Norad to promote institutional capacity building. Jones and Blunt (1999) support Askvik (1999) when they argue that the twinning approach can be seen in retrospect as a development in the early 1980s that resulted partly from dissatisfaction with the results delivered by the then conventional form of development co-operation known as TA. It aims to deal with the deficiencies of conventional development assistance by creating matching, pairing, and twinning between institutions with similar portfolios in developing countries and Norway. Accordingly, the basic assumption is that two institutions with the same tasks should learn from each other through sharing experience. In other words, twinning can be seen as a professional relationship between an operating institution in a developing country and a similar but more incoming institution in another part of the world. Franks (1998) supported by Cooper (1984) sees the twinning approach as "an increasingly important tool in providing opportunities for international co-operation and the sharing of knowledge, and for breaking down the barriers between problems and approaches in developed and developing economies,.... At a time when distinctions between the two are becoming increasingly blurred".

Notwithstanding the above definition by Franks (1998), the main pillars of the twinning approach for a developing country like South Africa are the provision of physical infrastructure in the form of buildings, vehicles and equipment, accompanied by high levels of formal education and training. TA will be delivered by specialists (often called experts) from the donor country who then visit the recipient country.

With practical experience in dealing with developmental programmes since 1994, it is not difficult to identify the elements of this approach and the assumptions behind it. In particular, it can be seen that learning of new developmental water services knowledge and skills via TA at an individual level may lead to an increased performance of a WSA or WSI as the case may be. The latter is due to the literature evidence that twinning approach aims to address the deficiencies of the conventional TA approach by shifting the emphasis from the development of individuals to institutions (Blunt, 1994; Blunt and Collins, 1994).

From the literature evidence it can be argued that the twinning approach can be explored to create partnerships between institutions with similar remits in South Africa (or developing country) and developed countries. (This twinning approach may probably include pairing cities, municipalities and water utilities in South Africa with those of developed countries). The current decentralisation and devolution of powers and functions to local government in South Africa provide an opportunity to explore the twinning approach amongst WSAs and WSIs alike. It is further argued that the challenges facing WSAs and WSIs provide us with a new implementation conceptual framework using the twinning approach in order to offer insights into these challenges. This should be built around the notion of institutional learning theories as tested by leading scholars such as Stryker (2001b), Van Ryneveld (2003), Argyris (2001), and Ngobese and Cock (1997). Certainly, within the context of developmental water services in South Africa at present, a twinning arrangement between WSIs and WSAs can create a more dynamic and proactive co-operation atmosphere for learning, and sharing experiences thereby promoting a systematic approach to decision-making processes on developmental water services problems, constraints and challenges including appropriate support and approaches thereof (Van Ryneveld and Sproule, 2005).

\section{Lessons from the literature for WSIs and WSAs in South Africa}

\section{Literature evidence on the need for a twinning approach}

From leading scholars such as Kolb et al. (1971), Argyris and Schön (1978) and Revans (1980), it is not difficult to understand the attraction of this idea, incorporating as it does the assertion that only WSAs and WSIs that are capable of learning will be able to effectively implement developmental water services reforms as per national targets. There is no doubt that the new developmental water services system in South Africa is posing major challenges to WSIs and WSAs to cope with. Capra (1988) expresses the implication of this challenge to newly established WSAs and WSIs as follows, though without prejudice: "[In South Africa, we need] a new paradigm....[and an international tried and tested approach between WSIs and WSAs in order to address technical skills and capacity constraints],...a new vision of reality, a fundamental change in our thoughts, perceptions and values [on how to deliver sustainable water services as per national targets]" (my emphasis).

In supporting the need for a new approach for meeting the intended outcomes of developmental water services, Bowers (1993) warns that "reform does not require a master plan before it begins; but it needs to be guided by a clear sense of direction in which we must move, and a full awareness of the consequences if we fail". In other words, WSAs and WSIs considering the twinning approach must avoid the top ten mistakes that cause paradigmatic change (re-engineering or redesigning water services) to fail as described by Hammar and Stanton (1995) pursuant to the limitations of the twinning approach implicitly and explicitly described by Berg (1993). 


\section{Twinning approach linkage to institutional learning strategies}

In view of the foregoing, it appears from literature evidence that institutions are more successful when they set attainable and consistent goals, specify how they will run themselves, and agree on steps to be taken to reach desired positions (Tsibani, 2004). It seems to be crucial to scan an environment and audit the institution's inventory of special skills and other resources. It is argued that effective institutions are ones whose strategies enable them to make the best of their capabilities and to capitalise on their surroundings in order to be institutionally specific.

However, strategies differ in two important ways:

- First is the stance toward action vs. learning. Institutions may emphasise either end of this continuum. Their strategies may stress efficiency, or how to put together known resources with little waste or they may stress innovation and the discovery of combinations of old and new resources that will change the institution's capacity for action.

- The second feature that distinguishes strategies is whether the focus of attention is principally internal or external. An internal orientation often tends to take the environment for granted. For instance, control and maintenance command the institution's foremost attention. Paradoxically, an external orientation favours engagement with the environment, watching it and trying to influence it. Neither end of these continua is fundamentally superior.

Which aspect of strategy any particular institution ought to accentuate depends on the complexity of two internal contingent elements (technology and structure), and on the hostility of the external environment. Furthermore, the right fit changes over time, as the institution faces new internal and external challenges. In support of this notion by Bowers (1993), Drucker (2001) points out, "doing things right," and not enough on "doing the right things."

In most cases, therefore, developmentally [oriented] water services institutions probably cannot sustain themselves through less reflective strategies. To emphasise learning is more often suitable in WSAs' and WSIs' settings in South Africa due to two overriding characteristics of institutions' constituencies:

- First, internal resources are scarce. This puts a premium on finding lean and mean structures and processes, to keep operations in line with changing resource endowments.

- Second, external conditions are turbulent. This may require various kinds of pre-emptive responses by institutions, if they are to remain focused on delivering affordable and sustainable water services. Unfortunately, the central tendency of water services institutions in South Africa is to downplay learning (Kiggundu, 1989).

It is easy to fall back on familiar routines during periods of crisis, and to forget experimentation with fresh approaches. This may hasten the institution's decline rather than sustain its turnaround, on one hand. On the other hand, it must be remembered that learning is not an end in itself. It consumes time and administrative energy. To the extent that learning is not immediately productive, it may even detract from an institution's ability to sustain itself.

\section{Twinning approach process for learning}

Based on the literature evidence, the following lessons are arrived at:

Formal, off-job training courses - useful primarily to enhance individual learning of knowledge transfer. It is well known that this type of training is the problem of transfer of learning from the classroom to the job. Twinning might help to overcome this problem if the more experienced organisation recognises it and helps its developing country partner to implement the necessary managerial support to enable individuals to put classroom-based learning into action back on the job.

In-house training courses - used for improving individual knowledge. The transfer of learning problem is less serious in this type of training, although it still needs attention. In twinning arrangements such courses are often supplied by short-term visiting consultants from the appointed advisors or consultants of the developed partner organisation, which can cause problems when, as sometimes happens, the consultants are not familiar with the environment or the most pressing needs. As argued above, maximum organisational benefit is likely to accrue when both partners are involved in all aspects of the course - learning needs analysis, planning, selection of trainers, implementation, assessment and evaluation. Additionally, such courses should ideally target work groups rather than individuals.

On-job training - probably the most effective training approach for skill improvement, because there are no learning transfer problems. In many development contexts this type of training is neglected, even resisted, either because its benefits are not recognised or because it does not offer formal qualifications. In a twinning arrangement this might be overcome if the experienced partner can demonstrate real benefits at both the individual and organisational level. This is more likely when on-job training is systematic and thoroughly evaluated.

Study visits - perhaps the most questioned practice, in cost/benefit terms, presenting two possibilities. They make it possible for representatives of the partner organisations to meet and become acquainted with each other's environment and operations, and they offer opportunities for these individuals to consider other possibilities. The assumption is that learning takes place from such visits, but this is unlikely unless they are carefully planned, with specified intended outcomes in terms of learning and action, and rigorous evaluation.

\section{Twinning guide for implementation in South Africa}

\section{Introduction}

A set of guiding ideas is the first element in designing a twinning arrangement. A guiding framework supplies the purpose and vision, which transcends the present through overarching values and a sense of ultimate direction to which the potential twinned institutions will be compelled to stay committed. In other words, the critical elements and processes to be followed in arranging a twinning approach serve as a new operational framework, structure, scaffolding or schemata within which twinning between institutions can be formalised. This will, inter alia, ensure that individual needs and constraints are clarified in order to ensure 
that proactive remedial actions are taken. It is proposed that this approach be used to facilitate a long-term relationship between two or more institutions, in the belief that by enhancing the performance of the developing partner, benefits will be produced downstream at the level of the department or agency's super-ordinate developmental water services strategic goals and targets.

\section{Critical elements of twinning institutions}

Inductively, the following emerge as distinguishing features of the twinning approach:

- Based on a partnership between two or more institutions

- Emphasis on sustainable organisational capacity building

- Relatively long-term nature of the twinning relationship or partnership.

There is a need for both potential partners or water services institutions to be provided with an opportunity to define their super-ordinate goals, i.e.:

- Their understanding of organisation- and institution-building

- Their view of sustainable organisational outcomes

- The nature of the desired relationship between the two or more institutions

- The optimal duration of the relationship

- The roles of the long-term team leader and advisers

- The selection of project staff; managing and maintaining the vitality of the relationship

- Termination of the relationship

This can, inter alia, limit some of the lessons learnt in various case studies between developed and developing countries described by Jones and Blunt (1999).

\section{Identifying suitable institutional partners}

The following factors would need to be taken into account in the establishment of organisational partnerships:

- The macro- and micro-contexts of both partners, including system compatibility, pace and direction of governance reform, infrastructure, language, etc.

- The most pressing needs of the developing country partner (or institution), that is, to what extent are they primarily technical or organisational or managerial

- The track record of the incoming partner, particularly the extent to which this reveals its level of understanding of the key issues and aims of development and its commitment to their realisation.

\section{Staff selection and the role of the long-term adviser}

Staff selection is critical to the success of organisational co-operation. The key position is the long-term adviser, whose role needs to be carefully defined and whose performance should be closely monitored. Selection for all adviser positions should be based on job analysis, to specify the technical and human requirements of the job.

The role of the long-term adviser is broad and demanding, involving more than technical advice and housekeeping. The adviser should be the strategic view finder and sensor for the incoming partner in order to ensure sustainability a twinning approach and implications thereof. As mentioned by Sutherland (1999) the advisor should play a strategic role for the developing partner without creating dependency. Therefore, the success of strategic management of the co-operation hinges largely on the way in which the adviser and the leadership of the developing partner tackle these issues together.

\section{Managing and maintaining the vitality of the relation- ship}

It is important that the excitement and interest that can be generated by the initiation of a twinning approach as a possible project must be maintained throughout the years of the relationship. Recognition of the reality of the twinning arrangement of WSAs and WSIs as a major process to give effect to developmental water services in South Africa can do a great deal to not only positively contribute to the much needed consolidation of LGDA phase but also vitalise the relationship over substantial periods of time. It is important that developmental agencies and potential partner institutions should recognise that the proposed project will be a major intervention in an existing institution, which will have both foreseen and unforeseen consequences. This is a contextual issue, which requires that the developed partners should have a detailed understanding of the potential South African WSAs and WSIs and their institutional environment for twinning approach as a project. As a result, the pre-project (preintervention) dialogue between the water services sector and/or stakeholders must concentrate on the major challenges, which the project (or possible twinning approach as an intervention) will present, beyond the operational considerations.

\section{Optimising the length of the relationship}

Sustainable capacity building is a complex and lengthy social science process, not amenable to precise target setting or measurement, and requiring judgement. It is not possible to specify precisely the appropriate duration for a twinning approach as a project. This paper demonstrates that each twinning project is unique and that tidy generalisation is not practicable. Partners need to make judgements about the likely duration of projects, informed by thorough analysis, at institutional and contextual levels. Judgements need to have flexibility, but it is important that stakeholders should know when the project is expected to be completed.

It is also advantageous if the twinned institutions are to agree on the planned phases of the co-operation within the intended total duration. This can help them to focus on institutional learning and capacity building, and reduce the tendency for managerial and institutional issues to be raised late in the co-operation, after the professional/technical development has been substantially completed. This can be ameliorated if the suggested stages are incorporated in the project planning, so that the co-operation is seen to have had a coherent schedule and a "natural" end.

\section{Benefits and outcomes of the twinning approach}

Based upon the aims and assumptions as discussed throughout this paper, the following benefits and outcomes are arrived at. They are, though not limited to:

- The twinning arrangement enhances the overall quality of the programme, by virtue of the fact that the special advisors repeatedly gained new insights from Sida and Norad 
- Better understanding of the problems needing to be tackled, and how best to address them

- The programme is flexible in order to individualised each problem or focus per organisation

- The twinning approach employs a mix of project techniques as part of or alongside the twinning arrangement

- It combines multidisciplinary teams of experts with different fields of specialisation, thereby enhancing technical competencies at operational, tactical and strategic levels respectively

- It gives greater credibility and sanctioning of the external expertise and specialists in the recipient institutions if roles and responsibilities on management and governance issues are clearly defined for accountability. For instance, RSA treasury regulations and constitutional matters must be known upfront.

- It promotes and enhances intra- and inter-relations between twinned institutions thereby promoting institution-to-institution exposure and a culture-of-learning organisation

- It stimulates team-work, institutional confidence and pride of their end-products and delivery mechanisms; and

- It provides greater flexibility in institutional capacity building and developmental water services delivery tools, models, and options.

In short, the realisation of the need for hands-on support under Municipal and Provincial Infrastructure Grants funding strategies and need for a new ways of support to deliver developmental water services, all seem to support the notion of twinning and partnering WSIs and WSAs in South Africa. The latter is due to the notion that such a twinning approach will, inter alia, strengthen "developmental water services" and foster its consolidation in general in South Africa. One executive manager cited by Sutherland (1999) put this need imposed by developmental water services for a twinning approach amongst WSAs and WSIs in South Africa succinctly: "higher education is not a panacea for South African governance...Higher education cannot address the current level of [municipal, provincial] and civil-service competence....South Africa has directors and directors-general, [permanent secretaries, municipal managers, municipal technical directors] with doctorates and little or no management experience. These persons who now run the government possess the conceptual skills to learn on the run, and therefore only need and only have time for 'on-the-job' coaching [training and mentorship] on the technology of bureaucracy-processes, systems, records, control, transparency... ways of dealing with all these things..."

\section{The way forward}

In the light of the above, it is logical to argue that an assessment of the environment moves beyond the immediate context of institutional co-operation and the conventional parameters normally associated with current capacity building and training support initiatives, to examine the broader governance context within which a twinning approach can be explored and exploited to make the best use of scarce resources. This is due to the notion that targeting for any institutional capacity building using a twinning approach depends on accuracy and efficiency when it is conducted on the basis of:

- A well-articulated partners' profiles base

- A thorough appreciation of the domains of development cooperation within the institutions at which particular lines of development co-operation will be directed
It is against this background that certain domains through an engagement process should be adopted leading to an implementation plan of action for the twinning approach. DWAF, DPLG, SALGA and other strategic partners in the water sector capacity building and training strategies have identified key focus areas for water sector and local government sector support irrespectively. The selection of these domains or key focus areas is critical for twinned partners or institutions to have a common vision, mission and strategic goals for the whole process and interrelationship of the programme thereof. It is envisaged that the following should be considered:

- The business plan is necessary to manage the whole process, define roles and responsibilities, form the basis of keeping the twinned institutions involved in the participation process and ensure that all the required outcomes receive attention

- The planning processes involve a consideration of all the issues and include community participation, financing, regulation, governance, provisioning, human resource management, transfer and so forth. They culminate in implementation processes mostly in accordance with formal agreements between the twinned institutions and other statutory organs of state and / or accountant officer/s

- The data that are needed for the processes, which include records such as asset registers and infrastructure plans, operating rules, etc.

The way forward would appear to lie in further developing the twinning approach, and establishing the necessary conditions or creating an enabling environment for twinning arrangements between institutions under which the approach's intended benefits and outcomes can most fruitfully be applied to WSAs and WSIs in South Africa including the SADC region in accordance with the NEPAD strategic objectives.

\section{Conclusion}

The paper has demonstrated that in most instances institutional capacity building is a relative term and a complex process, which requires ongoing and consistent engagement with stakeholders and relevant institutions. The twinning approach can also be a useful approach in supporting effective WSAs and WSIs, providing needed expertise and extending the range of learning environments. If this approach is guided by an inclusive consultation process by a competent partner, it can produce effective water services institutions and improvement of key performance areas of such beneficiary water services institutions. Like other forms of development co-operation, in the right context and with well-chosen and well-briefed partners, twinning can be the optimal approach to employ. Also, the importance and nature of mutual learning between the twinned water services institutions needs to be established at the beginning of projects and meanings need to be discussed and clarified then, rather than assumed. Operational aspects of twinning, such as staff selection and the management of the relationship should be given sufficient attention. Some ideas of domains of governance and domain hierarchies are recommended, arguing that judgements about the efficacy of developed partner interventions need to be situated within such a context. This can lead to a better position to produce persuasive arguments about water services project or programme targets, thereby ensuring sanctioning from the developing partner. 
For the developmental water sector regulation adopted by the central government (DWAF), this partnership or twinning approach appears to hold more long-term promises than traditional policing regulation. The latter is due to the notion that WSIs and WSAs are systems (A 'system' is described in basic text as: a set of inter-related parts, specified [or specifiable] relations between the parts; and a system boundary [implying a system environment] (see Alexander, 1974)). In other words, institutions are systems that require responsive and decisive systematic interventions in their business problems. In these situations, a twinning arrangement between systems, WSIs, WSAs or institutions offers, not a ready-made answer but, rather, a way of re-conceptualising the developmental water services challenges, and problems aforementioned. This pairing and twinning arrangement as implicitly and explicitly described throughout this paper, allows policy and decision-makers to illustrate a responsive and systematic approach to decision making which requires, inter alia, "all elements of the [developmental water services] problem to be set out under what, where, when and extent, and whether it is part of the problem or not,...in. other words, in order to narrow down the problem" (Van Ryneveld and Sproule, 2005).

Consequently, communication strategies and linkages are established to proactively address the problem rather than applying "carrots and sticks type of water regulation" (Stewart and Ayres, 2001). Yet, no one approach can supply all the raw materials needed for "developmental water services" challenges and development of appropriate intervention designs. Each approach, to use Weimer's words, "adds design concepts...to the capital stock of ideas commonly shared by policy analysts [water sector practitioners and leaders]" (Weimer, 1995).

\section{Recommendations for further research}

- Based upon literature evidence, it is recommended that this approach be implemented in various provinces and localities, particularly those with water services technical skills shortages including implementation constraints

- Whilst the twinning approach has certain benefits and outcomes for institutional development support for needy institutions, it is recommended that the approach not be regarded as the Deus ex machina for WSIs' and WSAs' historical legacy, illnesses, and constraints imposed by the external environment

- There is a need for a study of an appropriate duration of a twinning relationship, that is, how much time is necessary for realisation of its intended outcomes using comparative analysis as a methodology

- There is a need for an evaluation of the twinning approach particularly in African states in order to determine its impact as implemented by Sida and Norad in Africa in the early 1990 s

- There is also a need to explore this approach in terms of the proposed hands-on support or project consolidate as championed by DPLG to municipalities to accelerate implementation of MIG and people's contract.

- It would be critical if the Sida and Norad embassies in South Africa and elsewhere could co-host with a South African Government Department (DPLG \& DWAF) (including other strategic water services sector partners) a national seminar on the twinning method and its approach to address institutional capacity building amongst WSIs and WSAs identified and targeted under project consolidate. Critical theme would be: Twinning approach lessons in Africa and its implica- tions to people's contract in the new local government system in South Africa. This will, inter alia, provide South African policy-makers and decision-makers with appropriate lessons in their endeavours to support developmental water services.

\section{References}

ALEXANDER MJ (1974) Information Systems Analysis: Theory and Applications. Chicago: Science Research Associates.

ARGYRISC (2001) International barriers to decision-making. In: Harvard Business Review on Decision-Making. Harvard Review Paperback Series: Harvard Business School Press.

ARGYRIS C and SCHÖN D (1978) Organisational Learning: Theory, Method and Practice. Addison-Isley, Reading, MA.

ASK VIK S (1999) Twinning in Norwegian Development Assistance: a response to Jones and Blunt. Public Admin. Dev. 19 403-408.

BEER M and EISENSAT R (1996) Developing an organisation capable of implementing change and learning. Human Relations 49 (5).

BERG E (1993) Rethinking Technical Co-operation: Reforms for Capacity Building in Africa. UNDP, New York.

BLUNT P (1994)The cultural limits of process consulting in development assistance. In: Reineke RD and Sulzer R (eds.) Organisational and Management Consultancy in Developing Countries. Gabler, Berlin. 49-68.

BLUNT P (1995) Cultural relativism, 'good' governance and sustainable human development. Public Admin. Dev. 15 (1) 1-9.

BLUNT P (1997) Prisoners of the paradigm: process consultants and "clinical" development practitioners. Public Admin. Dev. 17 (1) 341-349.

BLUNT P and COLLINS P (1994) Introduction to special issue on Institution building in developing countries. Public Admin. Dev. 14 (2) $111-122$.

BLUNT P and JONES M (1997) Exploring the limits of western leadership theory in East Asia and Africa. Pers. Rev. 26 (1/2) 6-23.

BLUNT P (1996a) Towards a Re-formulation of the Programme Approach. UNDP/DOPP, New York.

BLUNT P (1996b) Participate Evaluation in Programmes Involving Governance Decentralisation: A Methodological Note. UNDP/ MDGD, New York.

BRIKKE F (2000) Operation and Maintenance of Rural Water Supply and Sanitation Systems: A Training Package for Managers and Planners: Operation and Maintenance Network of the Water Supply and Sanitation Collaborative Council, IRC International Water and Sanitation Centre (Online). Available from: http://www.irc.nl/page/1842 (Accessed on 24 March 2005).

BOWERS CA (1993) Education, Cultural Myths and The Ecological Crisis: Towards Deep Changes. New York: State University of the New York Press.

CAMPBELLMJ (1988) Towards a comparative theory of local government. In: Adamolekun L, Oluwu D and Laleye M (eds.) (1988) Local Government in West Africa since Independence. Lagos. 1-21.

CAPRAF (1988) The Turning Point: Science, Society And The Rising Culture. London; Fontana Paperbooks.

COOPER L (1984) The Twinning of Organisations. World Bank, Washington, DC.

DALE M (1994) Learning organisations. In: Mabey C and Iles P (eds.) Managing Learning. Open University, Milton Keynes.

DWAF (Department of Water Affairs and Forestry) (2001) Draft Water Sector Capacity Building and Training Strategy. Pretoria. Human Resource Development Directorate.

DEPARTMENT OF PROVINCIAL AND LOCAL GOVERNMENT (2001) Draft Capacity Building and Training Strategy. Pretoria.

DIXON N (1994) The Organisational Learning Cycle. McGraw-Hill, Maidenhead.

DRUCKER PF (2001) The effective decision. In: Harvard Business Review on Decision-Making. Harvard Business Review Paperback Series, Harvard Business Press. 1-19.

EDWARDS M (1997) Organisational learning in non-governmental organisations: What have we learned? Public Admin. Dev. 17235 250 . 
FRANKS T (1998) Capacity building: The ICID. Paper presented at the Conference of Directors of Special Courses, St Annes, April.

GLASSER W (1972) The Identify Society. New York: Harper and Row. GARRATT R (1987) The Learning Organisation. Fontana London.

HAMMARM and STANTON SA (1995) The Reengineering Revolution: The Handbook. London: Harper Collins Publishers.

JONES ML and BLUNT P (1999) Twinning as a method of sustainable institutional capacity building; In: Public Admin. Dev. 19 381-402.

KIGGUNDUMN (1989) Managing Organisation in Developing Countries. An Operational and Strategic Approach. Harare: Kumarian Press.

KOLB D RUBIN I and MCLNTYRE H (1971) Organisational Psychology: An Experiential Approach. Prentice-Hall, Englewood Cliffs, NJ.

MORAHEU (1996) Obstacles to optimal policy implementation in developing countries. In: Third World Planning Rev. 18 (1)79-105.

NGOBESE P and COOKJ (1997) Development and the Environment. In: Fitzgerald P, McLennan A and Munslow B (eds.) Managing Sustainable Development In South Africa ( $2^{\text {nd }}$ edn.). Oxford.

OLOWU D (1994) Beyond the failure of the Centralised State in Africa. In: Nothchild D (ed.) Strengthening Africa Local initiative Self-Governance, Decentralisation and Accountability. Hamburg Institut für Afrika-Kunde. 19-31.

PEDLER M, BURGONYNE J and BOYDELL T (1997) The Learning Company: A Strategy for Sustainable Development, McGraw-Hill, London.

REVANS RW (1987) International Perspectives on Action Learning. University of Manchester Institute for Development Policy and Management, Manchester.

REVANS RW (1980) Action Learning. Blond and Briggs, London.

UNDP (1997) Reconceptualising Governance. Division of Public Affairs, UNDP, New York.

SENGE P (1990) "The Fifth Discipline”: the Art and Practice of Learning, Doubleday, New York.

SENGE PM, ROBERTS C, ROSS RB, SMITH BJ and KLEINER A (1994) The Fifth Discipline Fieldbook: Strategies and Tools for Building a Learning Organisation. London; Nicolas Bearly Publishing.

SLATERD (1989) Territorial power and the peripheral state: The Issue of decentralisation. Dev. Change. 20. 501-531.

STEWART J and AYRES R (2001) Systems theory and policy practice: An exploration. Policy Sci. 34 .79-94.

STRYKER P (2001b) How to analyse that problem. In: Harvard Business Review on Decision Making. Harvard Business Paperback series, Harvard Business School Press. 113-142

SUTHERLANDS (1999) Supporting Democracy: The South Africa/ Canada Program on Governance .IDRC:Ottawa.

TSIBANI FG (2004) A Literature Review of Water Services Education and Training Needs of Councillors imposed by Developmental Local government Agenda. Mini-Thesis submitted to the University of Stellenbosch for Masters in Social Science Research Methods. Department of Sociology and Anthropology. Unpublished. 137 pp.

VAN RYNEVELD MB and SPROULE SL (2005) Knowledge Uptake by Technical Professionals and Decision-makers for "developmental water services". Draft Interim Report \#2: Knowledge Uptake. Report to the Water Research Commission. WRC report No: 4/05. $1-38$

WEIMER DL (ed.) (1995) Institutional Design. Boston:Kluwer Academic Publishers.

WORLD BANK (1997) World Development Report: The State in a Changing World. World Bank, Washington, DC.

\section{White Papers}

South Africa's national Housing Policy-March 2000.

The National Training Strategy Initiative-Working Group 9 of the National Training Board- 1994.

The White on the Reconstruction and Development Programme-1994.

Water Policy White Paper-April 1997.

Water Supply and Sanitation Policy White Paper-November 1994.

White Paper on Basic Household Sanitation -September 2001.

White Paper on Environmental management Policy- April 2000.

White Paper on Local Government-March 1998.

White Paper on Municipal Service Partnership-April 2000.

\section{Legislation}

Employment of Educators, Act No. 76 of 1998

Further Education and Training, Act No. 98 of 1998.

Intergovernmental Fiscal Relation, Act No. 97 of 1997.

Local Government Transition, Act No. 97 of 1996.

Manpower Training Amendment, Act No. 39 of 1990.

Pretoria: Government Printers.

South African Qualifications Authority, Act No. 58 of 1995

Skills Development, Act No. 97 of 1998.

Skills Development Levies, Act No. 9 of 1999

The Constitution of the Republic of South Africa, Act No. 108 of 1996.

The Division of Revenue, Act No. 5 of 2002.

The Draft Health Bill, 2001.

The Health, Act No.63 of 1977.

The Local Government Financial Management Bill, 2000 (in Parliament).

The Local Government: Municipal Demarcation, Act No. 27 of 1998.

The Local Government: Municipal Structures, Act No. 117 of 1998.

The Local Government: Municipal Systems, Act No. 32 of 2000.

The National Education Policy, Act No. 27 of 1996.

The National Water, Act No. 36 of 1998.

The Public Finance Management, Act No. 1 of 1999.

The Municipal Finance Management Act, Act 53 of 2003.

The Water Services Act, Act 108 of 1997. 
